\title{
Endobronchial Valve-Induced Pneumatocele: A Case Report
}

\section{Pneumatozele nach endobronchialer Lungenvolumenreduktion - ein Fallbericht}

Authors

Institutions
D. Skowasch', C. Pizarro' ${ }^{1}$, A. Valipour² , K. E. Wilhelm³ , D. Thomas³ ${ }^{3}$, G. Nickenig' ${ }^{1}$

${ }^{1}$ Department of Internal Medicine II - Cardiology/Pneumology, University of Bonn, Germany

${ }^{2}$ Department of Respiratory and Critical Care Medicine, Ludwig-Boltzmann-Institute for COPD, Otto Wagner Hospital Vienna,

Austria

${ }^{3}$ Department of Radiology, University of Bonn, Germany

\section{Bibliography}

Dol http://dx.doi.org/

10.1055/s-0033-1344640

Published online: 2.9.2013

Pneumologie 2013; 67: 639-640

(c) Georg Thieme Verlag KG

Stuttgart · New York

ISSN 0934-8387

Corresponding author

Prof. Dr. Dirk Skowasch

Department of Internal

Medicine II

University of Bonn

Sigmund-Freud-Str. 25

53127 Bonn, Germany

Dirk.Skowasch@

ukb.uni-bonn.de

\section{Abstract \\ $\nabla$}

We report a 75-year old female patient with advanced emphysema. After endoscopic lung volume reduction with endobronchial valves (EBV), a huge pneumatocele has occured and resolved spontaneously within a few weeks. Albeit rare, pneumatoceles should be considered in patients with relapsing dyspnoe after EBV treatment.

A 75-year-old woman with severe chronic obstructive pulmonary disease (COPD) and advanced emphysema (ex-smoker, 70 pack-years) was referred to our clinic for endoscopic lung volume reduction. She suffered from increasing dyspnea on exertion (6-minute-walk distance $240 \mathrm{~m}$ ) despite optimal medical treatment including tiotropium $18 \mu \mathrm{g}$ qd, salmeterol-fluticasone 50/500 $\mu$ g bid and long-term oxygen therapy. Pulmonary function tests showed a post-bronchodilator forced expiratory volume in $1 \mathrm{~s}$ of 0.671 ( $32 \%$ of predicted) and residual volume of 5.41 ( $245 \%$ of predicted). Computer tomography (CT) scan of the thorax confirmed heterogeneous emphysema with predominant manifestation in the upper lobes ( $\bullet$ Fig. 1a); left upper lobe was confirmed as the primary target lobe by a perfusion scan showing low perfusion $(8 \%)$ in this lobe. After bronchoscopic exclusion of collateral ventilation (Chartis system, Pulmonx Inc., Redwood City, CA, USA), 4 Zephyr endobronchial valves (EBV) (Pulmonx Inc., Redwood City, CA, USA) were placed in the left upper lobe/lingula through a flexible bronchoscope in order to suppress upper lobe ventilation and ultimately to improve lung mechanics, exercise performance and quality of life [1-3]. The procedure including assessment of collateral ventilation and EBV placement lasted $20 \mathrm{~min}$ and was uneventful.

\section{Zusammenfassung \\ $\nabla$}

Wir berichten über eine 75-jährige Patientin mit fortgeschrittenem Lungenemphysem. Nach endoskopischer Lungenvolumenreduktion (ELVR) mit Endobronchialventilen entwickelte sich eine große Pneumatozele, die sich spontan innerhalb weniger Wochen zurückbildete. Wenn auch selten, sollte eine Pneumatozele bei Patienten mit rezidivierender Dyspnoe nach ELVR mit in Betracht gezogen werden.

However, $24 \mathrm{~h}$ post-procedure the patient suffered from a symptomatic pneumothorax which was treated successfully by chest tube insertion. 4 days later a chest $\mathrm{x}$-ray suggested relapsing pneumothorax, and 5 days later, CT showed atelectasis of the left upper lobe (the objective of EBV treatment), the chest tube in situ and, surprisingly, a huge pneumatocele in the lingula ( $\bullet$ Fig. $1 \mathbf{b}$ ). Pneumatoceles are acquired, thin-walled, air-containing, intraparenchymal lesions of the lungs. In the present case, the localization of the pneumatocele is along the course of the fissure. Therefore, an interlobar pneumothorax could be another differential diagnosis, however, this would be characterized by a more oblong form and by intrafissural restriction due to previous pleural adhesions as a result of pleuodesis or pleural diseases - that are not known in the present case.

In accordance with the standard treatment of prolonged pneumothorax induced by EBV treatment, we removed 1 of the 4 valves one week after the primary procedure. However, the pneumatocele persisted without any significant change in size, while the atelectasis disappeared as expected ( $\bullet$ Fig. $1 \mathrm{c}$ ). Two of the remaining 3 valves were directly adjacent to the wall of the pneumatocele raising the possibility of bronchial obstruction by the EBV and thereby allowing one-way passage of air into the interstitial space. These 2 valves were therefore removed in a 3rd bronchoscopy whilst 


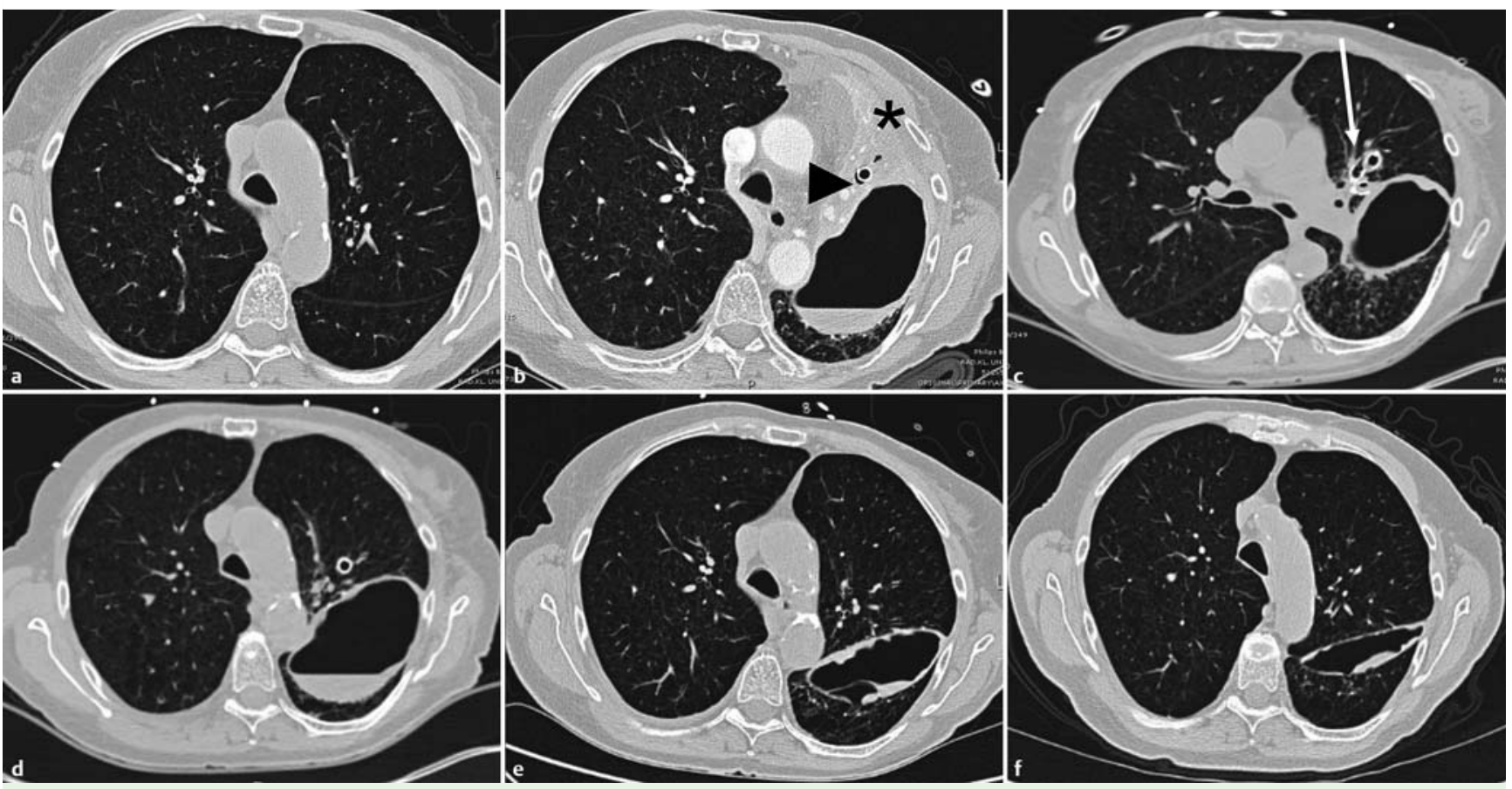

Fig. 1 Initial CT scan 2 months before EBV placement demonstrating advanced upper lobe predominant emphysema (a). CT scan on day 6 after treatment demonstrating atelectasis of the left upper lobe (arrow head), chest tube (asterisk) and the huge pneumatocele (b), CT control after removal of 1 EBV demonstrating direct adjacency of pneumatocele and EBV (arrow), CT follow-up after removal of 2 further EBV on days 9,12 and 20 demonstrating pneumatocele decreased in size $(\mathbf{d}-\mathbf{f})$.

the 4th EBV was left in place; during the same anesthesia, the chest tube was removed. Within the next 14 days, the pneumatocele significantly decreased in size without further invasive treatment ( $\bullet$ Fig.1d-f), and the patient could leave hospital. After 2 months, the patient presented in improved condition (6-minutewalk distance $320 \mathrm{~m}$; FEV1 1.01, 45\% of predicted; RV 4.91, 217\% of predicted), and the pneumatocele was resolved. Replacement of the removed EBV is not planned.

Clinical studies on 411 individuals revealed that complications of EBV treatment include pneumothorax, COPD exacerbation, pneumonia, hemoptysis and valve migration [1-3]. Whereas pneumothorax, usually appearing within $24 \mathrm{~h}$ ipsilateral to the non-treated lobe, is an expected event after EBV therapy in approximately $5-10 \%$ of cases, this is the first documented pneumatocele after EBV therapy. The exact pathogenesis of pulmonary pneumatoceles, commonly seen as a sequela of staphylococcal pneumonia in infants and young children [4] or after blunt pulmonary trauma, is uncertain [5]. In the present case, one may suggest a transient bronchial obstruction by the EBV as a checkvalve type. During inspiration, the obstruction may be partly relieved, allowing air to enter the interstitial space but not to leave it. The development of pneumatocele 3-5 days after EBV and pneumothorax favours the possibility that the combined scenario EBV plus distorted anatomy by the pneumothorax (and its resolution) causes the intraluminal obstruction with check-valve formation. Even after removal of 3 of the 4 EBV the pneumatocele persisted suggesting that the subsequently enlarged pneumatocele itself perpetuated the local bronchial obstruction.

Pneumatoceles should be considered and evaluated by CT in patients with relapsing or increasing dyspnea especially a few days after EBV treatment, when the patient normally has left hospital, or after an EBV-related pneumothorax has been treated. In the majority of cases, pneumatoceles resolve spontaneously within few weeks without invasive approaches [4,5]; invasive procedures should be evaluated only in case of complications such as tension pneumtocele or secondary infection.

\section{Conflict of Interest}

$\nabla$

The authors have no conflict of interest.

\section{References}

1 Sciurba F, Ernst A, Herth FJ et al. A randomized study of endobronchial valves for advanced emphysema. N Engl J Med 2010; 363: 1233-1244

2 Herth FJF, Noppen M, Valipour A et al. Efficacy predictors of lung volume reduction with Zephyr valves in a European cohort. Eur Respir J 2012; 39: $1334-1342$

3 Herth FJF, Eberhardt R, Gompelmann D et al. Radiological and clinical outcomes of using chartis to plan endobronchial valve treatment. Eur Respir J 2013; 41: 302-308

4 Kunyoshi V, Cataneo DC, Cataneo AJ. Complicated pneumonias with empyema and/or pneumatocele in children. Pediatr Surg Int 2006; 22: 186-190

5 Gavelli G, Canini R, Bertaccini $P$ et al. Traumatic injuries: imaging of thoracic injuries. Eur Radiol 2002; 12: $1273-1294$ 